\title{
A High-Gain, High-Voltage Pulse Generator using Sequentially-Charged Modular Multilevel Converter Sub-Modules, for Water Disinfection Applications
}

\author{
Mohamed A. Elgenedy, Student Member, IEEE, Ahmed M. Massoud, Senior Member, IEEE, Shehab \\ Ahmed, Senior Member, IEEE, and Barry W. Williams
}

\begin{abstract}
Modularity, redundancy and scalability are the key features recently sought in High-Voltage (HV) pulse generators for electroporation applications. Such features are gained by utilizing Modular Multilevel Converter (MMC) Sub-Modules (SMs). In this paper, two arms of MMC Half-Bridge SMs (HBSMs) are utilized for generating bipolar/unipolar HV pulses for disinfection process in water treatment applications. The HB-SM capacitors are charged sequentially from a low voltage dc input source via a resistive-inductive branch and a reverse blocking switch (which is turned ON/OFF at zero voltage/current conditions). The energy losses of the proposed capacitor charging technique are established mathematically as well as the charging time per SM-capacitor. Therefore, the proposed Sequential Pulse Generator (SPG) is able to generate high repetitive pulse rates with high efficiency regardless the HV level of the pulse. Different characterizations of bipolar rectangular pulses can be generated. The proposed topology is assessed by Matlab/Simulink platform and scaled down experimentation. The results establish the viability of the SPG topology for $\mathrm{HV}$ pulse generation for water disinfection applications.
\end{abstract}

Index Terms - Electroporation, high-voltage, Modular Multilevel Converter (MMC), pulse generator, pulse electric field, water treatment.

\section{INTRODUCTION}

$\mathrm{C}$ HLORINATION is commonly used for the disinfection process in water treatment applications [1]. Nevertheless, recent research established the effectiveness of applying Pulsed Electric Field (PEF) to disinfect water from harmful microorganisms (such as bacteria and E. coli) [2]. Successful disinfection is achieved by lethal electroporation; a process that produces electric pores in the biological cell membrane of the harmful microorganisms when subjected to High-Voltage (HV) pulses. The HV pulses are designed to create pores beyond a critical size at which the biological cell can reseal [3]. Typically, applying HV pulses of the kilo-Volt magnitude range $(1-100 \mathrm{kV})$ with pulse durations ranging between nanoseconds and milliseconds is sufficient for lethal electroporation [4].
Among different pulse-waveform shapes, rectangular pulses are preferred, as they have an effective pulse plateau [4]. Generally, rectangular pulses are generated either in unipolar or bipolar shapes. Bipolar rectangular pulses are advantageous in terms of subjecting the microorganisms under treatment to reversing mechanical stress in addition to the electrical stresses [5].

HV Pulse Generators (PGs) generate HV pulses. Traditionally, HV pulse generation is obtained using Marx generators, pulse forming networks, and Blumlein lines [6]. However, these PGs are bulky, inflexible, and inefficient [7]. Therefore, PGs based on semi-conductor switches represent an excellent candidate for the classical generators. In solid-state Marx PGs, obtaining HV pulses usually exploits the feature of charging a number of capacitors in parallel, then connecting them in series (by means of semi-conductor switches) to discharge across the load, creating the required HV pulse [8][10]. Conventional Capacitor-Diode Voltage Multipliers (CDVMs) have been utilized in [11] to generate HV pulses across the load, while in [12], the CDVM stages are modified by adding Insulated Gate Bipolar Transistors (IGBTs) such that all capacitors discharge across the load, and higher output voltage can be obtained.

The inherited capacitors in the Modular Multilevel Converter (MMC) Sub-Modules (SMs) can be used for HV pulse generation. Generally, MMC-based PGs can be classified into two main categories: PGs with HVDC input and those with Low Voltage (LV) DC input. In HVDC-based PGs, the utilized MMC arms are rated at the HVDC level, as a result, balancing the individual SM capacitors to a certain voltage is crucial. Also, protection against short circuit at the HVDC level is required. In contrast, LVDC-based PGs mainly suffer from low repetition rates, and are primarily targeting rectangular pulse-waveforms. They may need additional bidirectional switches in junction with the MMC-SMs. Utilizing the MMC Half-Bridge SM (HB-SM) shown in Fig.1, is explored in several publications [7], [13]-[17]. 

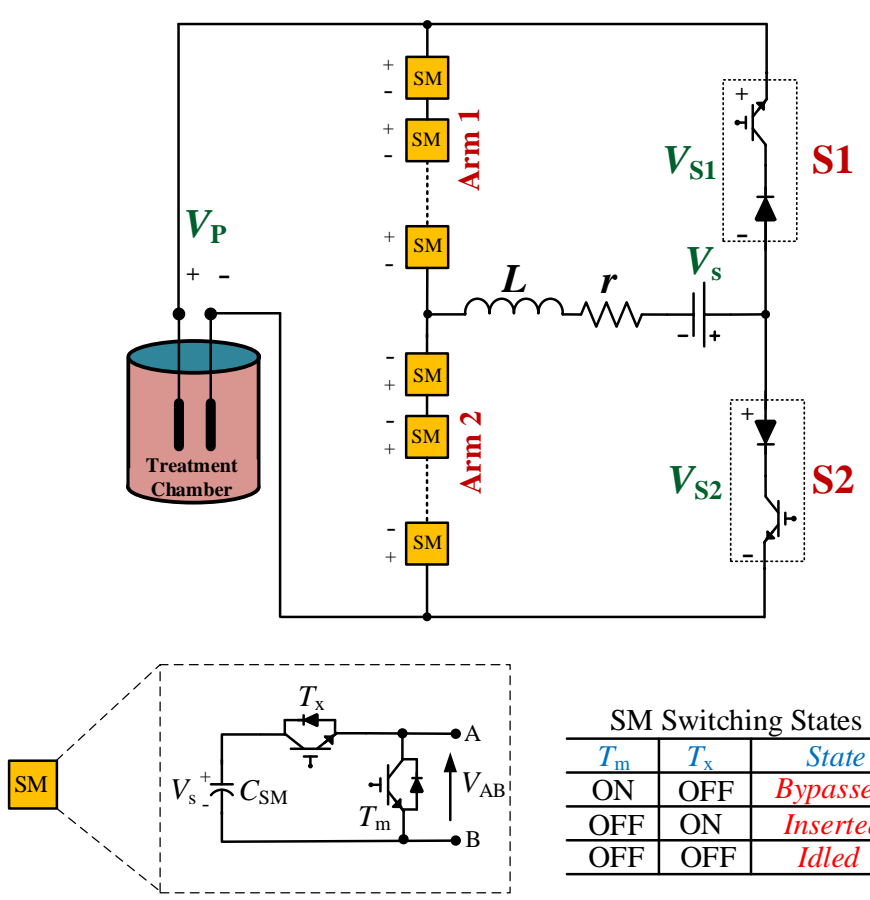

\begin{tabular}{c|c|c}
\multicolumn{4}{c}{ SM Switching States } \\
\hline$T_{\mathrm{m}}$ & $T_{\mathrm{x}}$ & State \\
\hline ON & OFF & Bypassed \\
\hline OFF & ON & Inserted \\
\hline OFF & OFF & Idled \\
\hline
\end{tabular}

Fig. 1. Proposed SPG topology.

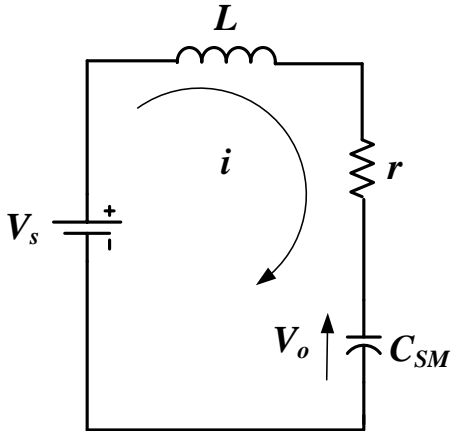

Fig. 2. Charging process equivalent circuit.
In [13]-[16], generating HV pulses is proposed using HVDC input supply. A common feature of these PG topologies is sensorless operation, where voltage balance of the SM capacitors is assured without any voltage measurements. In [13], a diode is added between the adjacent SMs, and with a proper switching of the individual SM IGBTs, voltage balancing is achieved. In [14], the capacitor voltage balancing is achieved through applying a specific modulation strategy to insert/bypass SMs. Although these techniques generate HV bipolar pulses, they only utilize half of the HVDC input voltage, and the operation deteriorates under SM failure. In contrast, in [15] an H-bridge, based on four arms of seriesconnected HB-SMs, is adopted. The pulse generation methodology assures sensorless SM capacitor voltages; operation under SM failure; and utilization of the full HVDC input, however, it requires a large number of SMs. In [16], with two HB-SM arms and two series-connected IGBT arms, forming an H-bridge fed from HVDC input, the SM capacitor voltages are measured and sorted continuously such that different pulse waveform shapes can be generated. In [7] and [17]-[18], a specific number of HB-SMs/Full-Bridge SMs (according to the required peak-pulse voltage) are charged sequentially from an LVDC input then discharged in series across the load, forming unipolar/bipolar HV pulses. But the charging mechanism is achieved via a relatively high charging resistances. Thus, the capacitors' charging time is elongated, which limits the generated repetition rate and/or the number of utilized SMs.

This paper proposes a bipolar HV PG fed from an LVDC input, based on the HB-SMs shown in Fig. 1. The proposed topology consists of two arms of series-connected HB-SMs, such that one arm, Arm1, generates a positive rectangular pulse polarity and the other arm, Arm2, generates a negative rectangular pulse polarity.

The SM-capacitors in each arm are charged sequentially from an LVDC input supply via a resistive-inductive $(r L)$ branch through a reverse blocking switch formed of an IGBT connected in series with a diode. The reverse blocking switch has a Zero-Voltage Switching (ZVS) at turning ON and a Zero-Current Switching (ZCS) at turning OFF. The efficiency of the adopted capacitor charging technique is proved mathematically to be controlled via the voltage-drop across the SM capacitors. Moreover, the individual SM-capacitor charging time is deduced. Therefore, the proposed Sequential PG (SPG) is able to generate high repetitive pulse rates with reduced energy loss and shorter charging time per SMcapacitor. Different characterizations of bipolar rectangular pulses can be generated, namely pulses:

- with/without combined periods of positive and negative Null Load Voltage (NLV),

- with different positive and negative voltage-peaks, and

- with different positive and negative durations.

Additionally, the required SM capacitance is small, leading to a reduced converter footprint. Although bipolar rectangular pulses are the main target of the proposed topology, it can be modified for unipolar pulse generation by utilizing only one arm of series HB-SMs of the desired polarity. Table I summarizes the key features of the proposed $P G$ in comparison with MMC-based PGs.

The validity of the proposed SPG converter is assessed via Matlab/Simulink simulations in addition to scaled-down experimentation. Results validate the proposed topology for water disinfection applications. 
TABLE I

SUMMARY OF THE KEY FEATURES OF MMC BASED PULSE GENERATORS

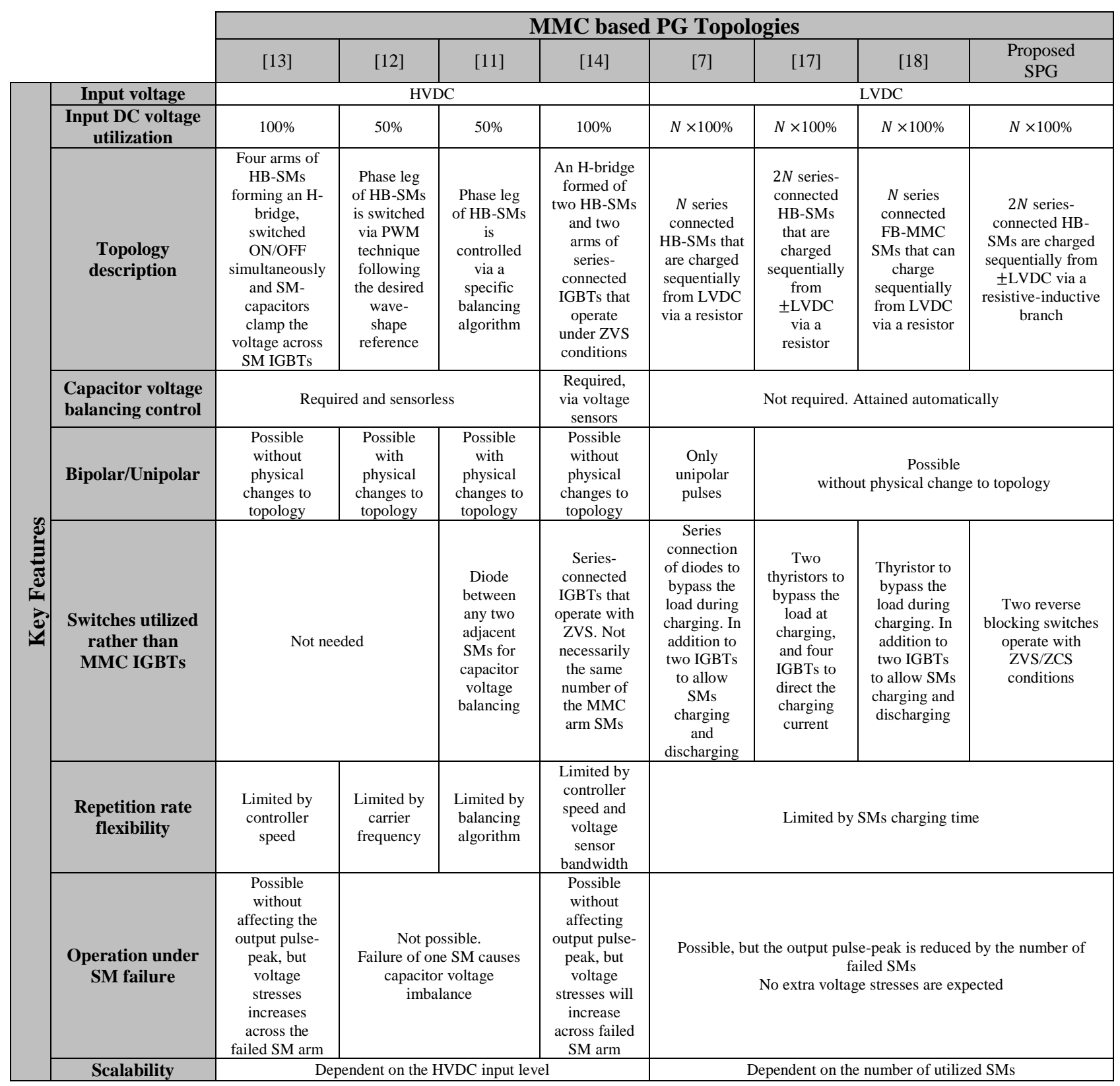

\section{SPG TOPOLOGY AND OPERATING PRINCIPLE}

The proposed SPG topology, shown in Fig. 1, is comprised of a combination of two series-connected HB-SM arms (Arm1 and Arm2) and two series-connected IGBT-diode switches (S1 and S2). Each HB-SM in Arm1 and Arm2 has a capacitor $C_{S M}$ in series with an auxiliary IGBT/diode $T_{x}$, and both are paralleled to a main IGBT/diode $T_{m}$. Each SM can operate in any of three switching states; bypass, insertion and idle, as shown in Fig. 1.
The arrangement of SMs and series IGBT-diode switches (S1 and S2) is such that the individual capacitors of the upper $N$ series-connected SMs, Arm1, are charged to $+V_{s}$ through $\mathrm{S} 1$ from input supply $V_{s}$. In contrast, the individual capacitors of the lower $N$ series-connected SMs, Arm2, are charged through S2 from the same input supply $V_{s}$ but in reverse polarity. The charging of each individual capacitor, either in Arm1 or Arm2, from the input supply is made sequentially via an $r L$ circuit, as shown in the charging equivalent circuit in Fig. 2. 


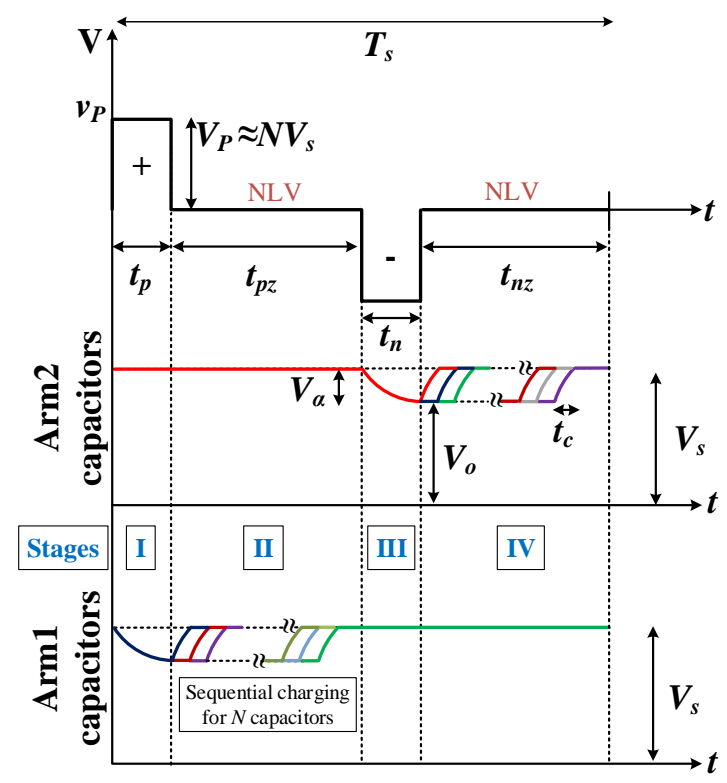

Fig. 3. SPG generated bipolar rectangular waveform and the corresponding charging/discharging sequence of Arm1 and Arm2 capacitors.

Generating a bipolar rectangular pulse of peak voltage $V_{P}=$ $\pm N V_{s}$, shown in Fig. 3, by the proposed SPG is achieved through the following stages (assuming all SM capacitors are pre-charged to $V_{s}$ ):

- $\quad$ Stage I: Arm1 SMs are inserted, and Arm2 SMs are bypassed, while the switches S1 and S2 are turned OFF as shown in Fig. 4a. Thus the load voltage is $+N V_{s}$ for the required positive pulse time $t_{p}$, and the supply $V_{s}$ is disconnected.

- Stage II: after contributing to the positive pulse generation; in Arm1, each SM capacitor voltage decreases to $V_{o}$ (as illustrated in Fig. 3). Thus, in stage II each capacitor is charged to $V_{S}$ sequentially. Arm1 and Arm2 are idled, while S1 and S2 are maintained OFF from stage I, then the first SM in Arm1 is inserted. Consequently, S1 is turned ON (hence, near ZVS is assured) and the charging process, for the charging time $\left(t_{c}\right)$, starts. After $t_{c}$, the charged SM is bypassed and the next SM is inserted for charging, etc. After the charging of the last SM capacitor, S1 is turned OFF (hence, ZCS is assured), then the SM is bypassed. During the total charging time of the $N$ sequentially-charged SMs, $t_{p z}=N t_{c}$, the load voltage is nulled as shown in Fig. $4 \mathrm{~b}$.

- Stage III: for a negative pulse period $t_{n}$, a negative pulse of peak $-N V_{s}$ is formed across the load by inserting Arm2 capacitors, while bypassing Arm1

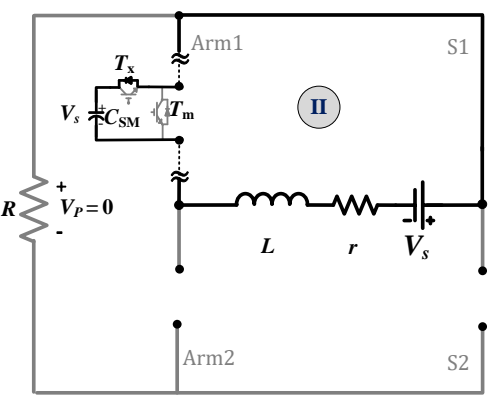

(b)

(a)

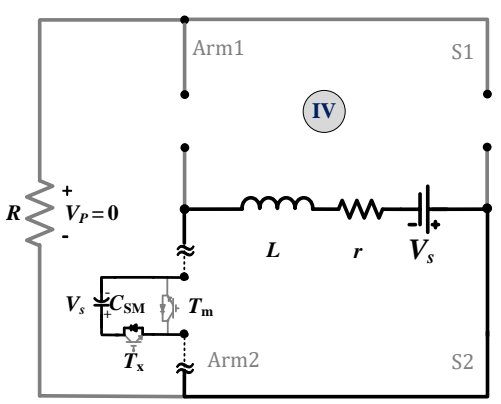

(c)

(d)

(d) g. 4. SPG circuit configurations
tage II. (c) Stage III. (d) Stage IV.

SMs, and maintaining S1 and S2 OFF as shown in Fig. 4c.

- Stage IV: similar to stage III, the negative NLV time $t_{n z}=N t_{c}$ is employed to sequentially charge the $N$ individual capacitors of Arm2 SMs through S2, see Fig. 4d, while imposing a zero voltage across the load. The same approach of turning ON/OFF S1 is repeated for S2 such that ZVS and ZCS are assured at S2 turn ON and OFF, respectively.

Since the positive and the negative arms of the seriesconnected HB-SMs are charged independently, generation of symmetrical, as in Fig. 3, as well as asymmetrical rectangular bipolar HV pulses is possible as shown in Fig. 5. As a result, the SPG allows flexible bipolar rectangular HV pulse generation in symmetrical and asymmetrical forms. In Fig. 5a symmetrical combined NLV durations pulse is shown when the pulse cycle starts with positive polarity. The asymmetry is not only in negative $\left(t_{n}\right)$ /positive $\left(t_{p}\right)$ pulse durations as in Fig. $5 b$, but also in negative $\left(V_{n}\right) /$ positive $\left(V_{p}\right)$ pulse magnitudes, as in Fig. 5c. Fig. 5d shows combining both asymmetries in a combined NLV pulse when the pulse cycle starts with negative polarity. As a result of pulse generation flexibility, if one or more of the SMs fails (then bypassed) the pulse voltage will be asymmetrical (in magnitude). In order to have the same energy content, the pulse width is increased as depicted in Figs. 5b and 5d. 


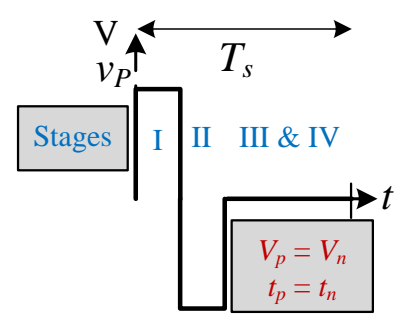

(a)

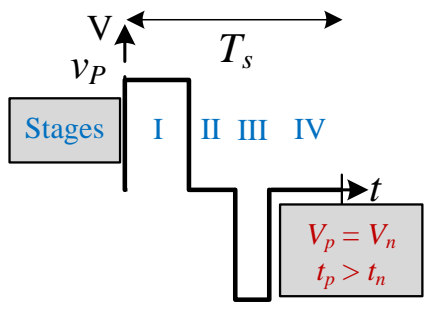

(b)

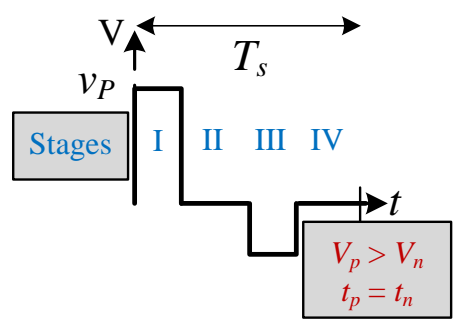

(c)

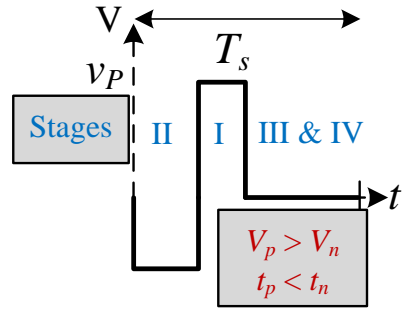

(d)

Fig. 5. Symmetrical and asymmetrical bipolar rectangular pulses. (a) Symmetrical combined NLV durations when the pulse cycle starts with positive polarity. (b) Duration asymmetry in bipolar rectangular pulses. (c) Magnitude asymmetry in bipolar rectangular pulses. (d) Asymmetrical combined NLV durations when the pulse cycle starts with negative polarity.

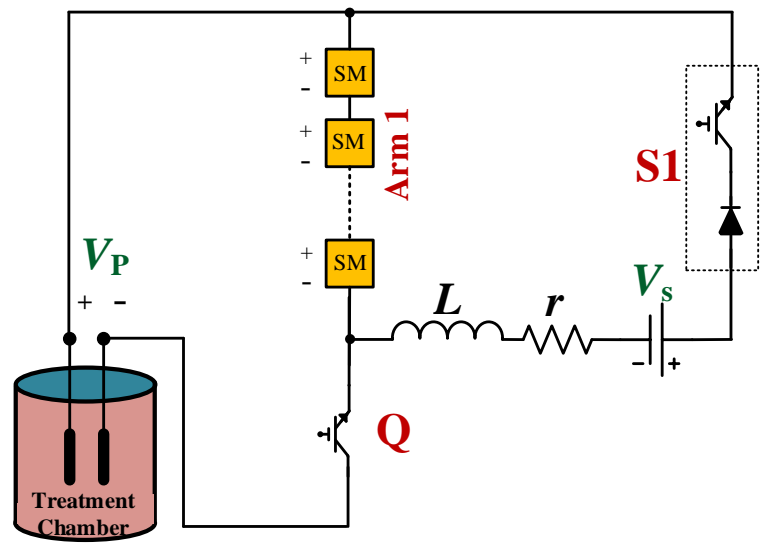

(a)

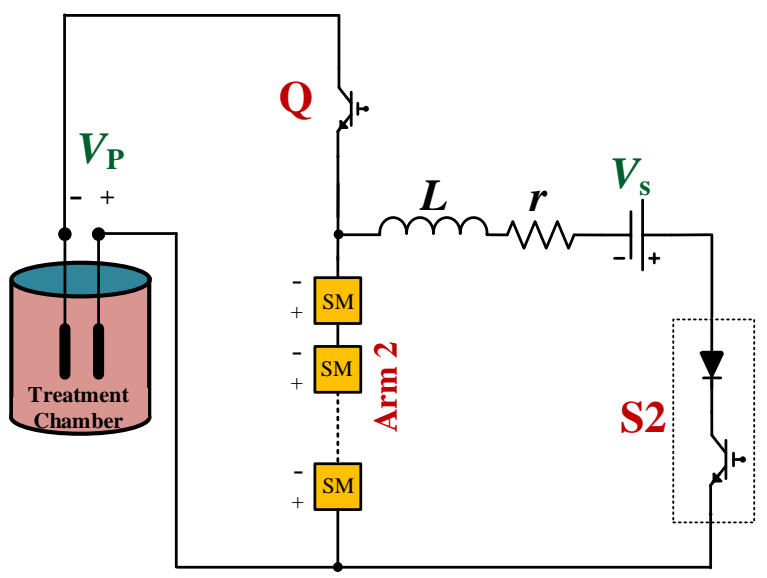

(b)

Fig. 6. Proposed SPG topologies for unipolar rectangular pulse generation. (a) Positive unipolar. (b) Negative unipolar.

For proper SPG operation, the IGBTs in the HB-SMs should be rated at the low voltage input dc supply $V_{s}$. Although, the IGBTs in $\mathrm{S} 1$ and $\mathrm{S} 2$ are rated at $V_{S}$, during positive and negative pulse generation, a reverse voltage of $(N-1) V_{S}$ is experienced across $\mathrm{S} 1$ and $\mathrm{S} 2$, respectively. Therefore a series diode to block such a voltage is necessary. Alternatively, any reverse blocking device, such as IGCT, can be utilized for S1 and S2 [19]-[20].

If unipolar pulses, with a specific polarity, are preferred using the topology in Fig. 1, the arm responsible for generating the other pulse polarity is disabled. However, it is more efficient and compact to replace the disabled HB-MMC arm with a single IGBT switch (Q) rated at $V_{s}$. Figs. $6 \mathrm{a}$ and $6 \mathrm{~b}$ show the proposed unipolar SPG topologies for positive and negative HV pulse generation, respectively.

Load modeling depends on the duration of the applied pulses [21]. Basically, the sample under treatment is modelled by series resistor and capacitor, and is linearly related to the resistivity of the medium and its dielectric constant, respectively. For a pulse duration comparable to the dielectric relaxation time (which is typically in nanosecond order) of the medium, the capacitive component of the impedance can be neglected [21]-[23]. Thus, the load can be described by resistance $(R)$, since the targeted range of pulse durations is in microseconds and higher, which are sufficient in water disinfection application.

\section{Charging Process ANALYsis AND SPG SM CAPACITANCE SIZING}

Consider the charging equivalent circuit in Fig. 2, where the SM-capacitor is initially charged to $V_{o}$ such that $V_{o}<V_{s}$ and the resultant capacitor voltage drop due to the previous voltage pulse generation is $V_{\alpha}=V_{s}-V_{o}$. Applying KVL yields:

$$
V_{s}=r i+L \frac{d i}{d t}+\frac{1}{C_{S M}} \int i d t
$$

Differentiate with respect to $t$ and re-arrange terms

$$
\frac{d^{2} i}{d t^{2}}+\frac{r}{L} \frac{d i}{d i}+\frac{i}{L C_{S M}}=0
$$

To solve this second-order differential equation; two initial conditions are required. Since at re-charging, the initial current is zero:

$$
i(0)=0
$$

Also, the capacitor voltage is reduced to $V_{o}$, after discharging across the load during pulse generation, hence, at $t=0$ applying KVL to find $\frac{d i(0)}{d t}$,

$$
r i(0)+L \frac{d i(0)}{d t}+V_{0}=V_{s}
$$

Thus,

$$
\frac{d i(0)}{d t}=\frac{V_{s}-V_{o}}{L}=\frac{V_{\alpha}}{L}
$$


TABLE II

RELATION BETWEEN $r, L$ AND $C_{S M}$ AND THE RESPONSE TYPE

\begin{tabular}{|c|c|c|c|}
\hline Response type & Overdamped & Critically damped & \multicolumn{1}{c|}{$C_{S M}=\frac{4 L}{r^{2}}$} \\
\hline Condition & $C_{S M}>\frac{4 L}{r^{2}}$ & Underdamped \\
\hline $\begin{array}{c}\text { Instantaneous } \\
\text { current equation }\end{array}$ & $i(t)=A_{1} e^{x_{1} t}+A_{2} e^{x_{2} t}$ & $i(t)=\left(A_{1}+A_{2} t\right) e^{-\alpha t}$ & $i(t)=e^{-\alpha t}\left(A_{1} \cos \omega_{d} t+A_{2} \sin \omega_{d} t\right)$ \\
\hline
\end{tabular}

Generally, the response of $i(t)$ depends on the roots of (2). The relation between $r, L$ and $C_{S M}$ that determines the response type and $i(t)$ mathematical expression are summarized in Table II. In Table II, $A_{1}$ and $A_{2}$ are constants to be calculated via the circuit initial conditions, $x_{1}$ and $x_{2}$ are the roots of the differential equation, which are expressed as in (6).

$$
x_{1,2}=-\alpha \pm \sqrt{\alpha^{2}-\omega_{o}^{2}}
$$

where $\alpha=\frac{r}{2 L}, \omega_{o}=\frac{1}{\sqrt{L C_{S M}}}$ and $\omega_{d}=\sqrt{\omega_{o}^{2}-\alpha^{2}}$.

\section{A. Individual SM Capacitor Charging Efficiency}

Since a critically damped response represents the margin between the other two response types, it is considered in the following analysis without loss of generality. The current $i(t)$ can be expressed as follows, while taking the initial conditions into account,

$$
i(t)=\frac{V_{\alpha}}{L} t e^{-\alpha t}
$$

The energy dissipated in $r$ can be expressed as $E_{r}$ where

$$
E_{r}=r \int_{0}^{\infty} i(t)^{2} d t=\frac{r V_{\alpha}^{2}}{L^{2}} \int_{0}^{\infty} t^{2} e^{-2 \alpha t} d t
$$

The integration yields

$$
\begin{gathered}
E_{r}=\frac{r V_{\alpha}^{2}}{L^{2}}\left[\frac{-e^{-2 \alpha t}\left(2 \alpha^{2} t^{2}+2 \alpha t+1\right)}{4 \alpha^{3}}\right]_{0}^{\infty} \\
E_{r}=\frac{r V_{\alpha}^{2}}{L^{2}} \frac{1}{4 \alpha^{3}}
\end{gathered}
$$

Since $\alpha=\frac{r}{2 L},(10)$ yields

$$
E_{r}=\frac{r V_{\alpha}^{2}}{L^{2}}\left(\frac{8 L^{3}}{4 r^{3}}\right)=\frac{2 L}{r^{2}} V_{\alpha}^{2}
$$

However, for a critically damped response type, $C_{S M}=\frac{4 L}{r^{2}}$; substitution in (11) gives

$$
E_{r}=1 / 2 C_{S M} V_{\alpha}^{2}
$$

The energy supplied $E_{s}$ by the source $V_{s}$ is

$$
E_{s}=V_{s} \int_{0}^{\infty} i(t) d t=\frac{V_{s} V_{\alpha}}{L} \int_{0}^{\infty} t e^{-\alpha t} d t
$$

Integrating yields

$$
E_{s}=\frac{V_{s} V_{\alpha}}{L}\left[\frac{-e^{-\alpha t}(\alpha t+1)}{\alpha^{2}}\right]_{0}^{\infty}=\frac{V_{s} V_{\alpha}}{L} \frac{1}{\alpha^{2}}
$$

Similarly, since $\alpha=\frac{r}{2 L}$ :

$$
E_{s}=\frac{V_{s} V_{\alpha}}{L}\left(\frac{4 L^{2}}{r^{2}}\right)=V_{s} V_{\alpha} \frac{4 L}{r^{2}}
$$

Again, for a critically damped response, $C_{S M}=\frac{4 L}{r^{2}}$; substitution into (15) gives

$$
E_{s}=C_{S M} V_{s} V_{\alpha}
$$

The per unit (pu) charging inefficiency $\left(\eta_{\text {loss }}\right)$ is expressed as

$$
\eta_{\text {loss }}=\frac{E_{r}}{E_{s}}=\frac{1 / 2 C_{S M} V_{\alpha}^{2}}{C_{S M} V_{s} V_{\alpha}}=\frac{1 / 2 V_{\alpha}}{V_{s}}
$$

Thus, the pu voltage drop determines the inefficient energy $\left(\% \eta_{\text {loss }}\right)$ thus the charging energy efficiency $\left(\% \eta_{c h}\right)$, as follows:

$$
\begin{aligned}
& \% \eta_{\text {loss }}=100 \times 1 / 2 V_{\alpha}^{p u} \\
& \% \eta_{\text {ch }}=100-\% \eta_{\text {loss }}
\end{aligned}
$$

Regardless the response type ( $r C$ or under or over damped $r(L)$, the inefficiency always dependant on the capacitor voltage drop. Inductance does not influence the efficiency, but affects the charging current peak and capacitor charging time.

\section{B. Individual SM Capacitor Charging Time}

Generally, for given initial conditions, the overdamped case has the longest charging time while the underdamped case has the fastest charging time. If a fast response, without severe oscillations or ringing, is desired, the critically damped case is used. In this paper, the response of the circuit is chosen to be underdamped with near unity damping factor. This provides a fast charging time with acceptable overshoot and negligible oscillation. The underdamped current is expressed as

$$
i(t)=\frac{V_{\alpha}}{\omega_{d} L} e^{-\alpha t} \sin \omega_{d} t
$$

After charging the individual SM capacitor, the charging current is reduced to zero, hence, the actual charging time $t_{c}^{*}$ can be calculated by setting $i\left(t_{c}^{*}\right)=0$, solving (20) for $t_{c}^{*}$ yields:

$$
t_{c}^{*}=\frac{\pi}{\omega_{d}}
$$

Accordingly, the software-controller assigned charging time, $t_{c}$, for each SM capacitor must be larger than $t_{c}^{*}\left(t_{c}>t_{c}^{*}\right)$ such that the charging current drops to zero, therefore, assuring ZCS of the IGBT.

\section{Individual SM Capacitor Sizing}

The energy transferred to the resistive load per pulse polarity is expressed as [16]:

$$
E_{L}=\frac{N^{2} V_{s}^{2}}{R} t_{p l}
$$


TABLE III

SIMULATION AND EXPERIMENTAL SPECIFICATIONS

\begin{tabular}{|l|c|c|c|}
\hline \multicolumn{2}{|c|}{ Parameter } & Simulation & Experimental \\
\hline LVDC input voltage & $V_{S}$ & $1 \mathrm{kV}$ & $200 \mathrm{~V}$ \\
\hline Load pulse peak voltage & $V_{P}$ & $10 \mathrm{kV}$ & $600 \mathrm{~V}$ \\
\hline Input inductance & $r L$ & $1 \Omega$ and $2 \mu \mathrm{H}$ & $2 \Omega$ and $6 \mu \mathrm{H}$ \\
\hline Number of SMs per Arm & $N$ & 10 & 3 \\
\hline Load resistance & $R$ & $1 \mathrm{k} \Omega$ & $500 \Omega$ \\
\hline SM capacitance & $C_{S M}$ & $5 \mu \mathrm{F}$ & $5 \mu \mathrm{F}$ \\
\hline $\begin{array}{l}\text { Assigned SM charging } \\
\text { time }\end{array}$ & $t_{C}$ & $20 \mu \mathrm{s}$ & $60 \mu \mathrm{s}$ \\
\hline Repetition time & $T_{S}$ & $420 \mu \mathrm{s}$ & $400 \mu \mathrm{s}$ \\
\hline $\begin{array}{l}\text { Percent remaining } \\
\text { voltage }\end{array}$ & $\beta$ & \multicolumn{2}{|c}{$>$} \\
\hline Safety factor & $\gamma$ & 1.3 & 3.2 \\
\hline
\end{tabular}

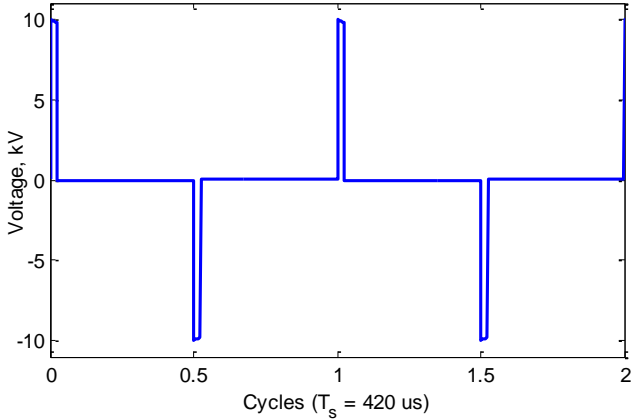

(a)

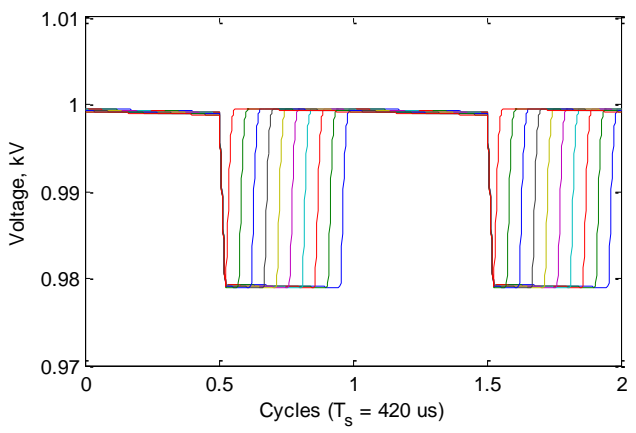

(c)

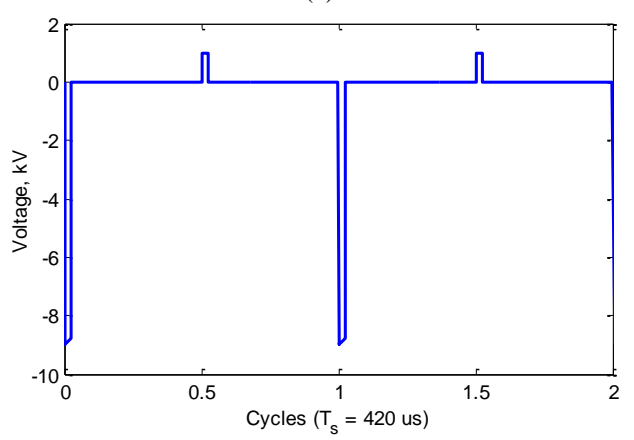

(e) where $E_{L}$ is the per pulse-polarity load energy and $t_{p l}$ is the pulse-polarity duration. Accordingly, the load energy is transferred from the stored energy in the series inserted SM capacitors during pulse generation, hence

$$
1 / 2 N C_{S M} V_{s}^{2}\left(1-\beta^{2}\right)=\frac{N^{2} V_{s}^{2}}{R} t_{p l}
$$

where $\beta$ is the percentage remaining voltage on the SM capacitor after pulse generation. Thus, the SM capacitance is

$$
C_{S M}=\frac{2 N t_{p l}}{\left(1-\beta^{2}\right) R}
$$

To account for the neglected voltage drops across the semiconductor switches and parasitic resistances, a safety factor $\gamma \geq 1$ is introduced. Accordingly, the SM capacitance used in the proposed topology is selected based on

$$
C_{S M}=\frac{2 N \gamma t_{p l}}{\left(1-\beta^{2}\right) R}
$$

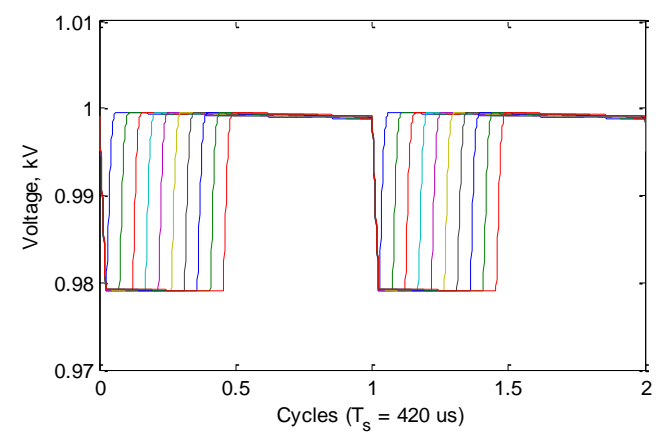

(b)

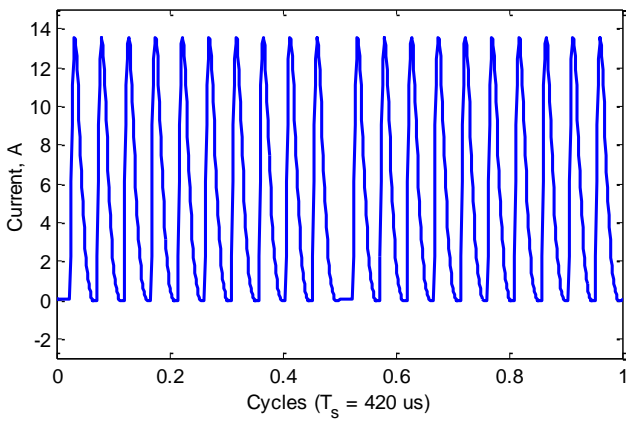

(d)

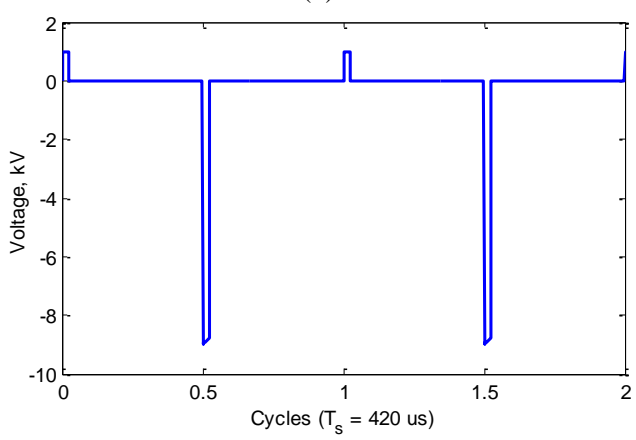

(f)

Fig. 7. Generation of $10 \mathrm{kV}$ peak, $10 \mu \mathrm{s}$ symmetrical bipolar pulses. (a) Voltage pulses across the load. (b) Ten SM capacitor voltages of Arm1. (c) Ten SM capacitor voltages of Arm2. (d) Input charging current of the SM capacitors. (e) Voltage across S1. (f) Voltage across S2. 


\section{Simulation Results}

In order to assess the viability of the proposed SPG topology, Matlab/Simulink simulations are used, with the specifications in Table III.

With a $10 \mu \mathrm{s}$ pulse duration and $10 \mathrm{kV}$ pulse peak, symmetrical bipolar voltage pulses are depicted in Fig. 7. The SM capacitors in Arm1 and Arm2 are charged through the $r L$ branch sequentially to the LVDC supply level $V_{s}=1 \mathrm{kV}$. Fig. 7a shows the generated pulses across the load while Figs. $7 \mathrm{~b}$ and $7 \mathrm{c}$ illustrate the charging and discharging sequence of the positive and negative SM capacitors, respectively. The input charging current for one cycle is shown in Fig. 7d, where the 20 SMs of Arm1 and Arm2 are charged sequentially in the positive and negative NLV periods, respectively. Based on the parameters in Table III, the individual SM capacitor charging current drops to zero after the charging time, $t_{c}^{*}=16.2 \mu \mathrm{s}$, as a result, in the software controller, the assigned charging time for each SM capacitor is set to $t_{c}=20 \mu \mathrm{s}$.
Thus, after charging the last SM capacitor, switches S1 and S2 can be turned OFF safely at ZCS. The voltage stresses across $\mathrm{S} 1$ and $\mathrm{S} 2$ are shown in Figs. 7e and 7f.

Symmetrical combined NLV durations are shown with a positive pulse generated first and with a negative pulse generated first, with $10 \mu$ s pulse duration and $10 \mathrm{kV}$ pulse peak in Figs. 8a and 8b, respectively.

In Fig. 9, the generation of asymmetrical bipolar pulses is explored. Bipolar pulses with a positive peak of $V_{p}=10 \mathrm{kV}$ and a negative peak of $V_{n}=5 \mathrm{kV}$ with $10 \mu$ s pulse duration for each polarity are shown in Fig. 9a. With $10 \mathrm{kV}$ voltage peak, Fig. $9 \mathrm{~b}$ shows bipolar pulses of positive pulse duration $t_{p}=$ $15 \mu$ s and negative pulse duration $t_{n}=5 \mu \mathrm{s}$. Combined NLV duration pulses of $V_{p}=5 \mathrm{kV}, t_{p}=15 \mu \mathrm{s}, V_{n}=10 \mathrm{kV}$, and $t_{n}=5 \mu$ s are shown in Fig. 9c. The combined NLV duration pulses of $V_{n}=4 \mathrm{kV}, t_{n}=15 \mu \mathrm{s}, V_{p}=5 \mathrm{kV}$ and $t_{p}=5 \mu \mathrm{s}$ are shown in Fig. 9d.

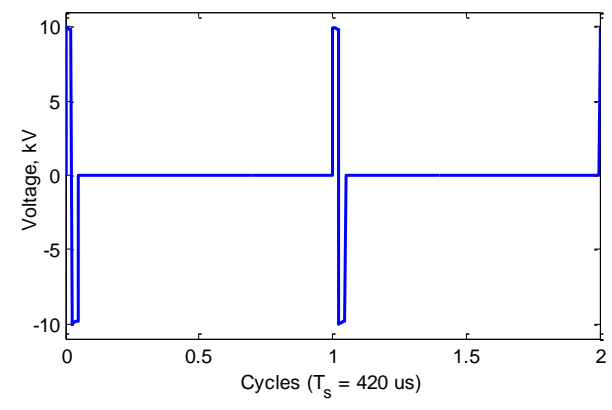

(a)

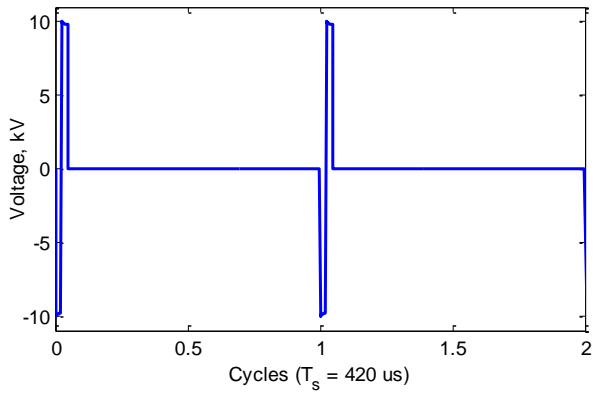

(b)

Fig. 8. Generation of $10 \mathrm{kV}$ peak, $10 \mu \mathrm{s}$ symmetrical combined NLV durations bipolar pulses. (a) Positive pulse generated first. (b) Negative pulse generated first.

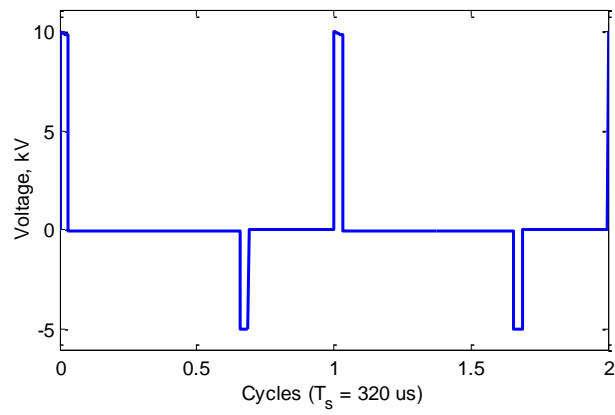

(a)

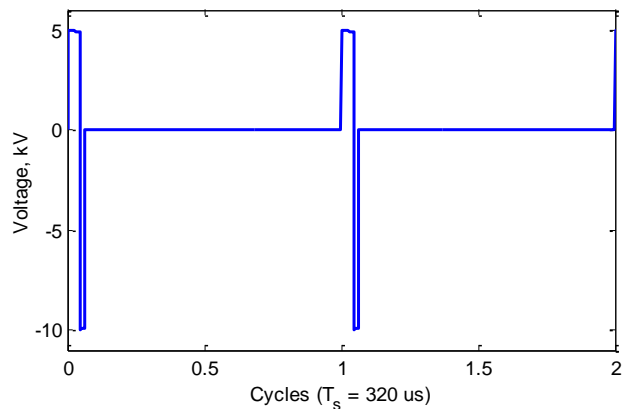

(c)

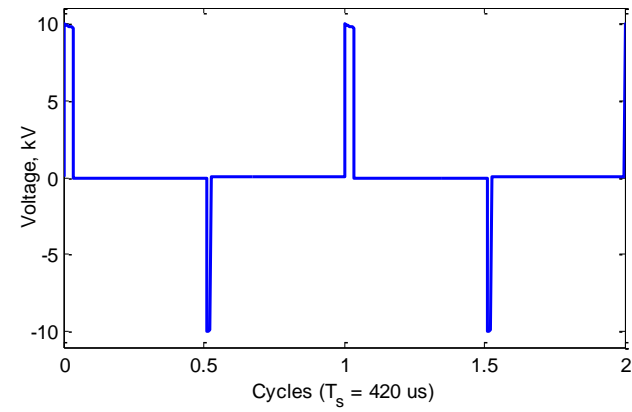

(b)

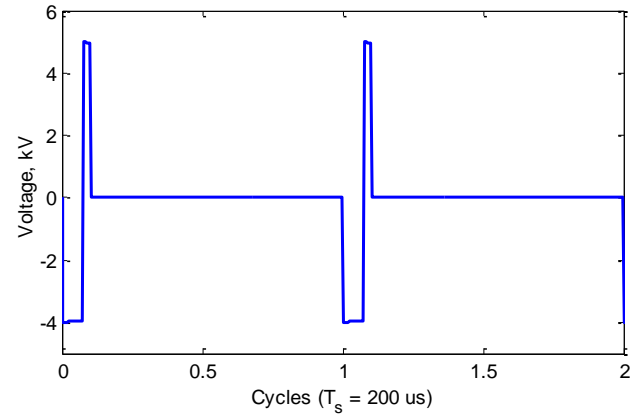

(d)

Fig. 9. Generation of asymmetrical bipolar pulses. (a) Positive and negative polarities magnitude asymmetry. (b) Positive and negative polarities duration asymmetry (c) Asymmetrical pulses with combined NLV durations when the pulse cycle starts with positive polarity. (d) Asymmetrical pulses with combined NLV durations when the pulse cycle starts with negative polarity. 


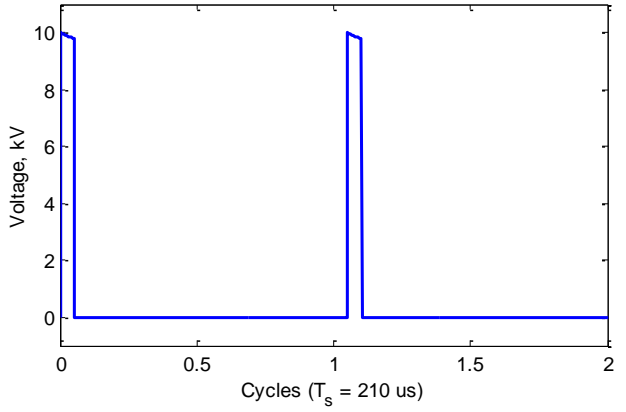

(a)

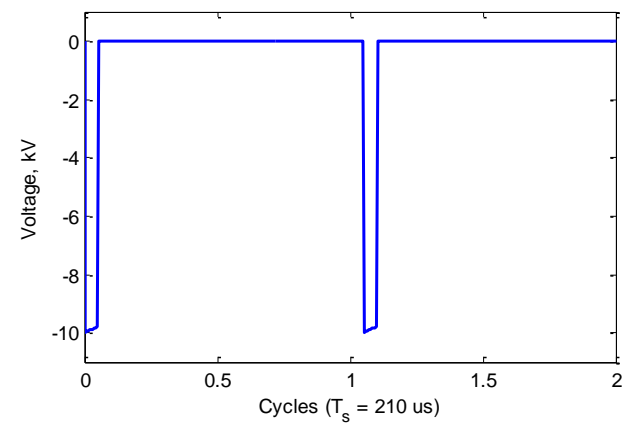

(b)

Fig. 10. Generation of $10 \mathrm{kV}$ peak, $10 \mu$ s unipolar pulses. (a) Positive pulse polarity. (b) Negative pulse polarity.

With the parameters in Table III and the unipolar SPG topologies illustrated in Fig. 6, unipolar pulses of peak voltage $10 \mathrm{kV}$, duration of $10 \mu \mathrm{s}$ and repetition rate of $T_{s}=210 \mu \mathrm{s}$ are generated are shown in Fig. 10. Fig. 10a shows unipolar pulses of positive polarity while Fig. 10b shows negative polarity unipolar pulses.

Table IV shows a quantitative comparison between the proposed SPG topology and the MMC-based sequential charging topologies using a charging resistor in [7], [17]-[18].
The comparison is based on generating HV pulses with a pulse peak voltage $V_{P}=10 \mathrm{kV}$, repetition time $T_{s}=500 \mu \mathrm{s}$ (for unipolar mode $T_{s}=250 \mu \mathrm{s}$ ), and pulse duration time $t_{p l}=$ $20 \mu$ s across a $R=1 \mathrm{k} \Omega$ resistive load. As shown in Table IV the capacitance in the sequential charging topologies in [7], [17]-[18] is 60\% larger than for the proposed SPG topology. But the maximum current of the sequential charging topologies in [7], [17]-[18] is $23.3 \%$ lower than in the proposed SPG topology.

TABLE IV

QuANTITATIVE COMPARISON BETwEEn SEQUENTIAL CHARgING MMC-BASEd PULSE GENERATORS

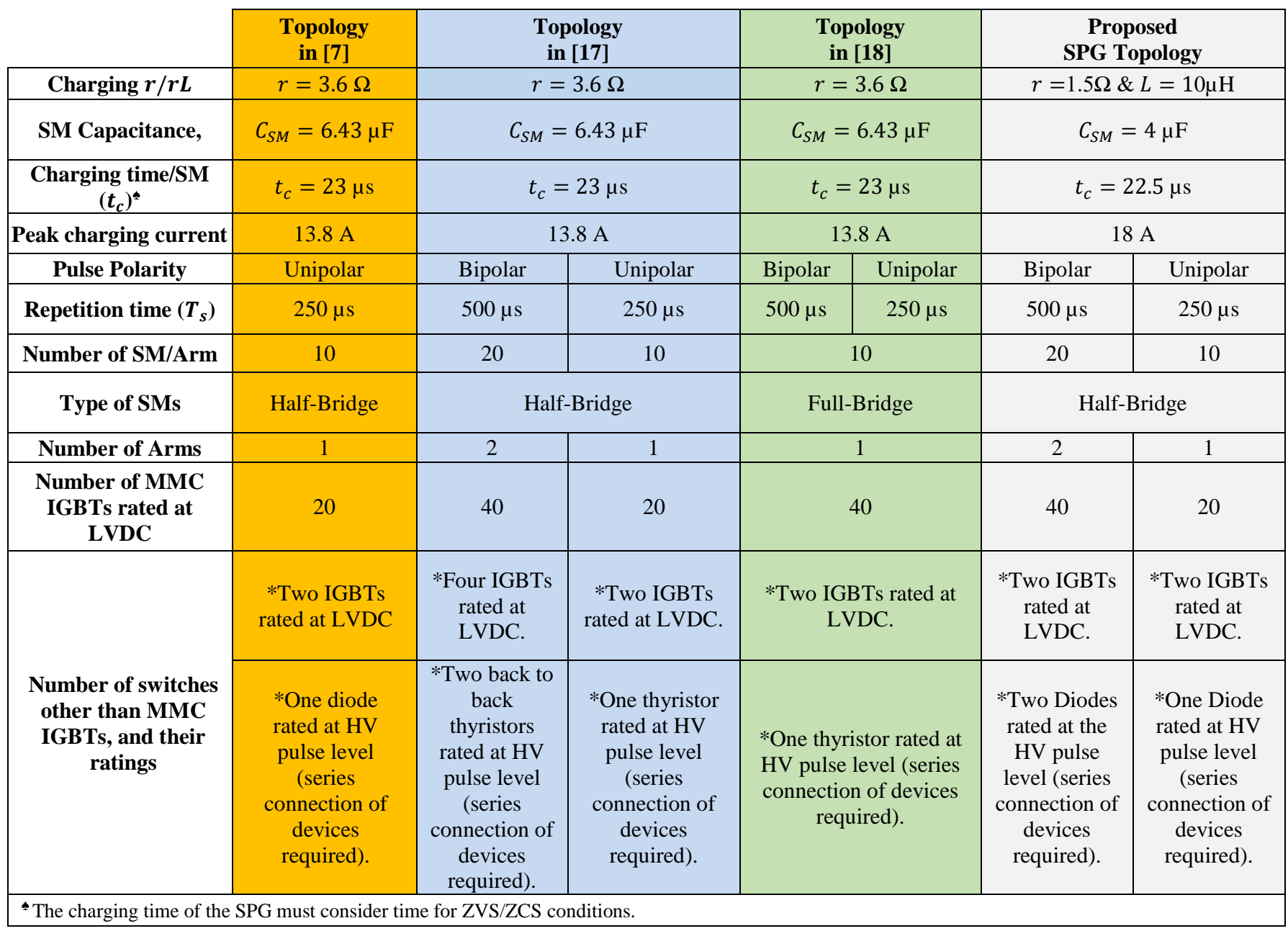


Furthermore, in the bipolar pulse generation mode, the proposed SPG can have the same repetition time as the unipolar pulse generator, where one of the upper and one of the lower SMs can be charged simultaneously, but at the expense of doubling the current drawn from the input supply. This feature is not possible in the PG topologies in [7], [17][18] due to their hardware structure.

\section{EXPERIMENTAL RESULTS}

The scaled-down SPG power circuit of Fig. 1 uses IGBT switches (STGW30NC60WD) in the HB-MMC arms, which have antiparallel diodes, while switches S1 and S2 are comprised of (Infineon IGW60T120) IGBT in series with (IXYS DSEI30-10A) ultrafast power diode.

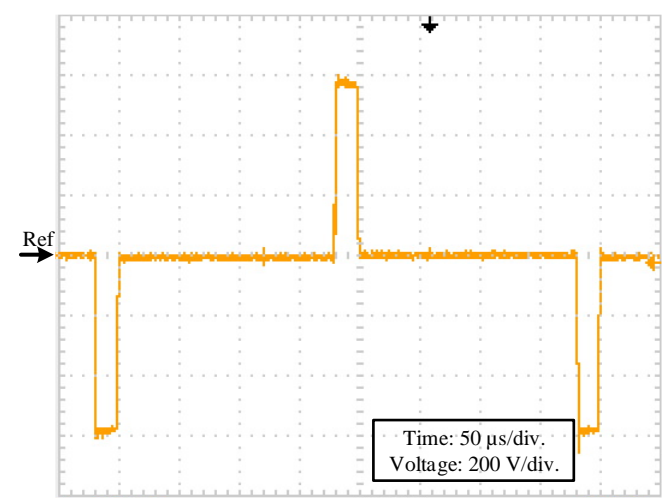

(a)

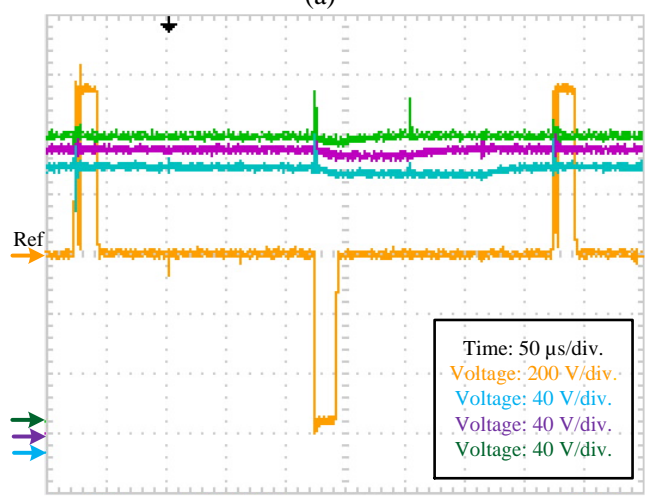

(c)

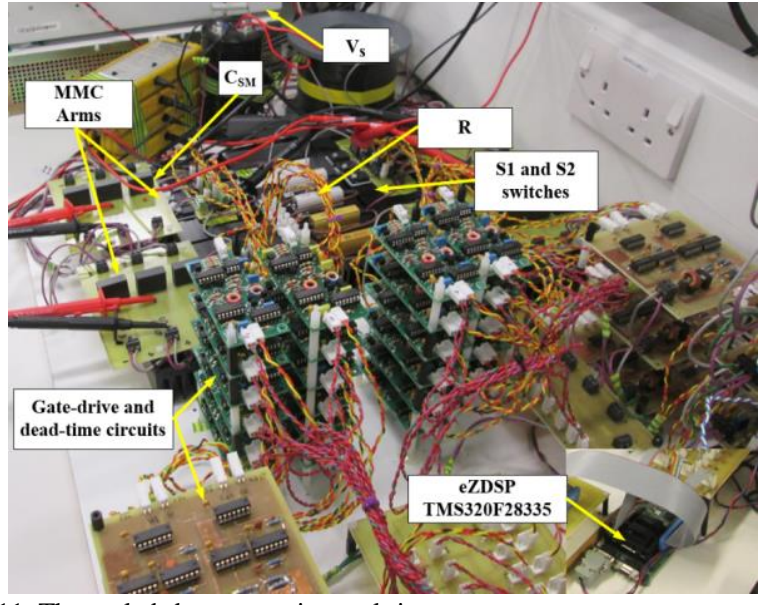

Fig. 11. The scaled-down experimental rig.

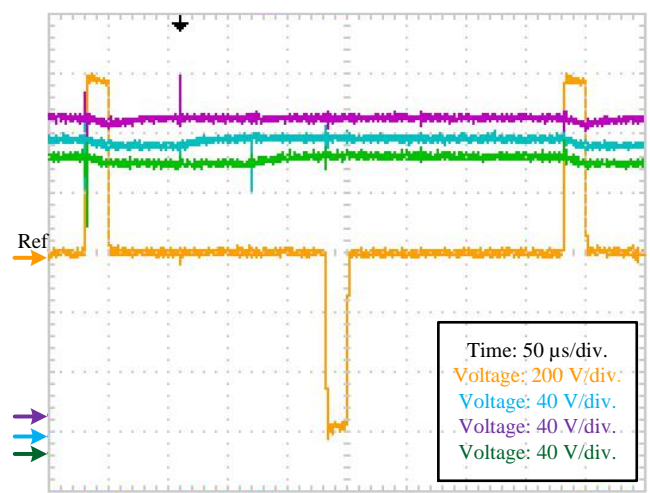

(b)

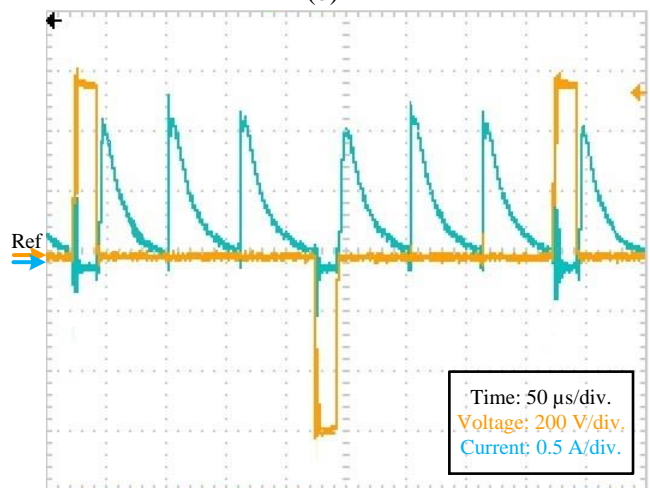

(d)

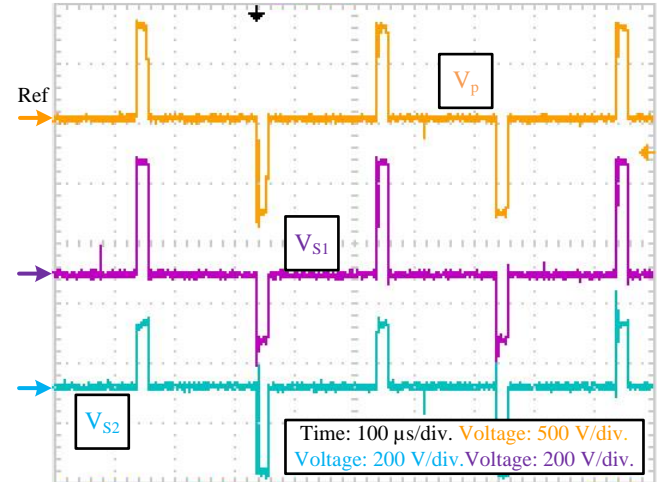

(e)

Fig. 12. Experimental generation of symmetrical bipolar pulses of $1.2 \mathrm{kV}$ peak-peak. (a) Output voltage pulses. (b) Positive arm, Arm1, SM-capacitors voltage charging and discharging sequence. (c) Negative arm, Arm2, SM-capacitors voltage charging and discharging sequence. (d) Input charging current. (e) Voltage waveforms across switches S1 and S2. 
The software algorithm was implemented in a Texas Instruments (TMS320F28335) DSP to generate the required gating signals for the SPG switches. The experimental specifications are given in Table III, and the scaled-down experimental rig is shown in Fig. 11.

Fig. 12 shows the generated symmetrical bipolar pulses with a peak-peak voltage of $1.2 \mathrm{kV}, 20 \mu$ s pulse duration and $T_{s}=400 \mu$ s repetition rate. The generated voltage pulses are shown in Fig. 12a, while Figs. 12b and 12c show the charging and discharging sequence of the positive and negative arm SM-capacitors, respectively. In order to generate a peak voltage of $600 \mathrm{~V}$ per pulse-polarity, the individual SM capacitors are sequentially charged to the supply voltage $V_{s}=$ $200 \mathrm{~V}$. The input charging current is shown in Fig. 12d with assigned SM charging time $t_{c}=60 \mu \mathrm{s}$. The voltage waveforms across switches $\mathrm{S} 1$ and $\mathrm{S} 2 \quad\left(V_{S 1}\right.$ and $V_{S 2}$, respectively) are depicted in Fig. 12e, measured as illustrated in Fig. 1.
During pulse generation each switch opposing to the inserted SM-capacitors is subjected to a reverse voltage of $V_{P}-V_{S}=400 \mathrm{~V}$, while the other switch is subjected to $V_{S}=$ $200 \mathrm{~V}$.

Generated asymmetrical bipolar pulses are shown in Fig. 13. $1.2 \mathrm{kV}$ peak-peak, bipolar pulses of $t_{p}=20 \mu \mathrm{s}$ and $t_{n}=$ $10 \mu$ s are shown in Fig. 13a. Combined NLV durations bipolar pulses of $V_{p}=600 \mathrm{~V}, t_{p}=10 \mu \mathrm{s}, V_{n}=200 \mathrm{~V}$ and $t_{n}=20 \mu \mathrm{s}$ are shown in Fig. 13b. Pulse duration of $20 \mu$ s combined NLV durations bipolar pulses of $V_{p}=100 \mathrm{~V}$ and $V_{n}=400 \mathrm{~V}$ are shown in Fig. 13c.

Unipolar pulses are generated by enabling the desired pulse polarity arm only, as shown in Fig. 14. Positive unipolar pulses are shown in Fig. 14a with a peak voltage of $600 \mathrm{~V}$, pulse duration of $10 \mu \mathrm{s}$ and repetition rate of $T_{s}=190 \mu \mathrm{s}$. Fig. $14 \mathrm{~b}$ shows negative unipolar pulses with peak voltage of 600 $\mathrm{V}$, pulse duration of $20 \mu \mathrm{s}$, and a repetition rate of $T_{s}=200$ $\mu \mathrm{s}$.

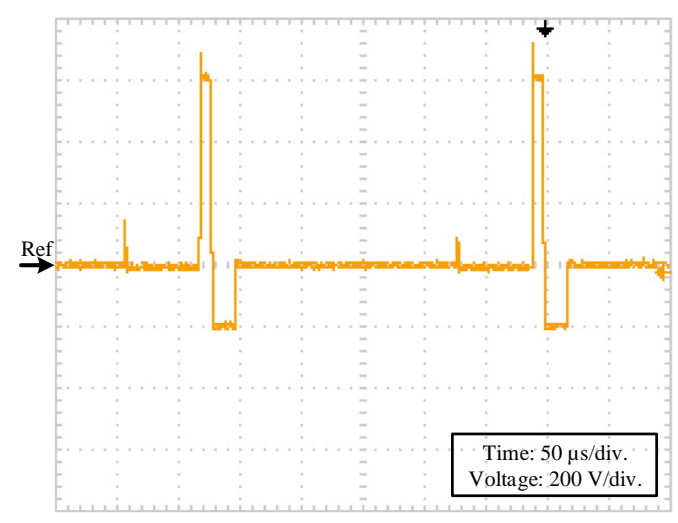

(b)

(a)

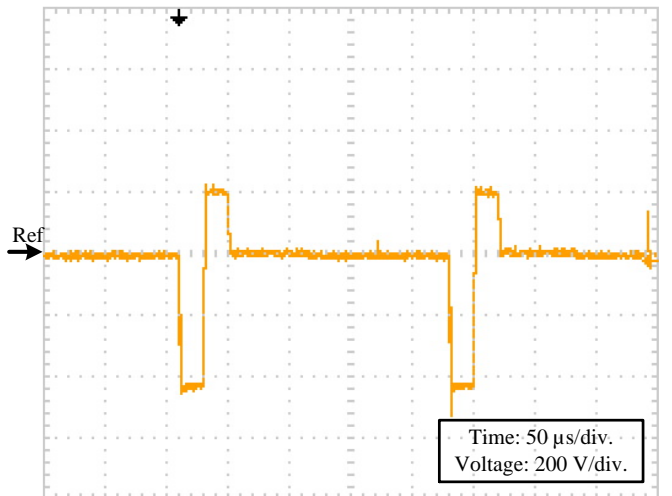

(c)

Fig. 13. Experimental generation of asymmetrical bipolar pulses. (a) Positive and negative polarities duration asymmetry. (b) Positive and negative polarities magnitude and durations asymmetry with combined NLV durations when pulse cycle starts with positive polarity. (c) Positive and negative polarities magnitude and durations asymmetry with combined NLV durations when the pulse cycle starts with negative polarity. 


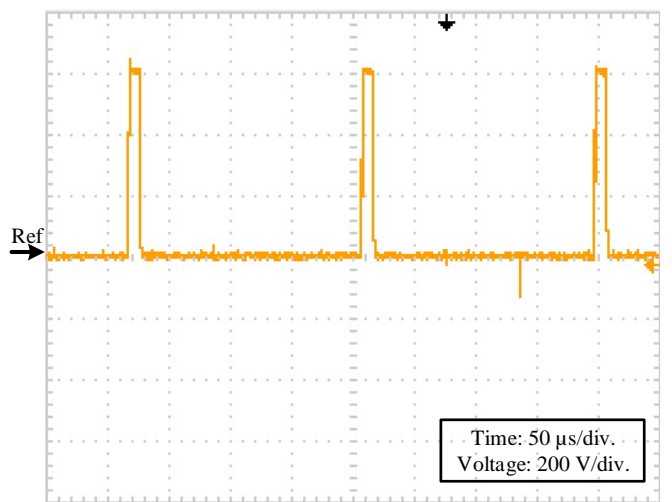

(a)

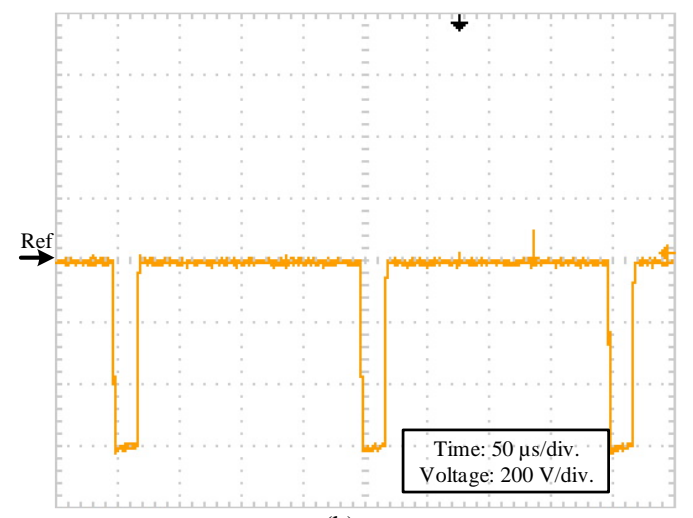

(b)

Fig. 14. Experimental generation of $600 \mathrm{~V}$ peak unipolar pulses. (a) Positive pulse polarity with $10 \mu$ s pulse duration. (b) Negative pulse polarity with $20 \mu$ s pulse duration.

\section{CONCLUSION}

Complying with the emerging requirements of HV PGs such as redundancy, modularity, flexibility and scalability; this paper presented a new PG topology. The proposed PG topology is fed from an LVDC supply and the circuit configuration comprises two arms of series connected HBSMs MMC (Arm1 and Arm2) in addition to two reverse blocking switches S1 and S2, forming an H-bridge. HV pulse generation is possible by sequentially charging the SM capacitors during the generated pulse null load voltage durations through a resistive-inductive branch and reverseblocking switches (which turn ON/OFF at ZVS/ZCS conditions). The proposed SPG topology is able to generate $\mathrm{HV}$ bipolar rectangular pulses with flexible properties in magnitude and duration for both pulse polarities. The SPG mainly targets bipolar pulses, which have the merit of subjecting the sample under treatment to mechanical stresses and electrical stresses. Unipolar pulse generation is possible by deactivating the undesired pulse polarity arm. The capacitance size of the individual MMC-SMs is established to be small, in comparison to that a HB-MMC used in HVDC transmission applications; hence, the proposed converter has a smaller footprint. The efficiency of charging was proved mathematically to be controlled by the voltage-drop across the SM capacitors, due to conducting the pulse. The explored features of the proposed SPG topology via simulations and scaled-down experimentation, confirm the viability of the SPG for disinfection process in water treatment applications. The main contribution of the proposed SPG can be summarized as:

- It employs an LVDC input supply.

- It has the ability of generating unipolar/bipolar rectangular pulses with controllable voltage peak and duration.

- The number of sequentially charged SMs is a function of the required boosting ratio.

- It does not require voltage sensors.
The SM capacitors are charged from the LVDC supply via a resistive-inductive branch, which allows a controlled underdamped current to flow, and charges the capacitors swiftly, hence, higher repetitive rates are possible with controlled charging current peak.

\section{ACKNOWLEDGMENT}

This work was supported by the Qatar National Research Fund (a member of the Qatar Foundation) under NPRP Grant (7-203-2-097). The statements made herein are solely the responsibility of the authors.

\section{REFERENCES}

[1] Water Treatment Manual: Disinfection, Office of Environmental Enforcement, Environmental Protection Agency-EPA, Wexford, Ireland, 2011.

[2] A. Abou-Ghazala, S. Katsuki, K. H. Schoenbach, F. C. Dobbs, and K. R. Moreira, "Bacterial decontamination of water by means of pulsed-corona discharges," IEEE Trans. Plasma Sci., vol. 30, pp. 1449-1453, 2002.

[3] S. H. Jayaram, "Sterilization of liquid foods by pulsed electric fields," IEEE Electr. Insul. Mag., vol. 16, pp. 17-25, 2000.

[4] H. Bluhm, Pulsed power systems: principles and applications, Berlin, Springer, 2006.

[5] K. H. Schoenbach, R. P. Joshi, R. H. Stark, F. C. Dobbs, and S. J. Beebe, "Bacterial decontamination of liquids with pulsed electric fields," IEEE Trans. Dielect. Elect. Insulation, vol. 7, no. 5, pp. 637-645, 2000.

[6] J. Raso and V. Heinz, Pulsed electric fields technology for the food industry: Fundamentals and applications. London, U.K. Springer, 2006.

[7] A. A. Elserougi, A. M. Massoud, and S. Ahmed, "A modular highvoltage pulse-generator with sequential charging for water treatment applications," IEEE Trans. Ind. Electron., vol. 63, pp. 7898-7907, 2016.

[8] L. M. Redondo and J. F. Silva, "Repetitive high-voltage solid-state marx modulator design for various load conditions," IEEE Trans. Plasma Sci., vol. 37, pp. 1632-1637, Aug. 2009.

[9] S. Bae, A. Kwasinski, M. M. Flynn, and R. E. Hebner, "Highpower pulse generator with flexible output pattern," IEEE Trans. Power Electron., vol. 25, pp. 1675-1684, 2010.

[10] T. Sakamoto, A. Nami, M. Akiyama, and H. Akiyama, "A repetitive solid state marx-type pulsed power generator using multistage switch-capacitor cells," IEEE Trans. Plasma Sci., vol. 40, pp. 2316-2321, 2012. 
[11] A. Elserougi, A. M. Massoud, A. M. Ibrahim, and S. Ahmed, "A high voltage pulse-generator based on dc-to-dc converters and capacitor-diode voltage multipliers for water treatment applications," IEEE Trans. Dielectr. Electr. Insul., vol. 22, no. 6, pp. 3290-3298, 2015.

[12] M. R. Delshad, M. Rezanejad, and A. Sheikholeslami, "A new modular bipolar high-voltage pulse generator," IEEE Trans. Ind. Electron., vol. 64, no. 2, pp. 1195-1203, 2017.

[13] L. Lamy Rocha, J. F. Silva, and L. M. Redondo, "Multilevel highvoltage pulse generation based on a new modular solid-state switch," IEEE Trans. Plasma Sci., vol. 42, pp. 2956-2961, Oct. 2014.

[14] A. A. Elserougi, A. M. Massoud, and S. Ahmed, "Modular multilevel converter-based bipolar high-voltage pulse generator with sensorless capacitor voltage balancing technique," IEEE Trans. Plasma Sci., vol. 44, pp. 1187-1194, 2016.

[15] M. A. Elgenedy, A. Darwish, S. Ahmed, and B. W. Williams, "A modular multilevel-based high-voltage pulse generator for water disinfection applications," IEEE Trans. Plasma Sci., vol. 44, pp. 2893-2900, 2016.

[16] M. A. Elgenedy, A. Darwish, S. Ahmed, and B. W. Williams, "A transition arm modular multilevel universal pulse-waveform generator for electroporation applications," IEEE Trans. Power Electron., vol. 32, no. 12, pp. 8979-8991, 2017.

[17] A. Elserougi, A. Massoud, and S. Ahmed, "Conceptual study of a bipolar modular high voltage pulse generator with sequential charging," IEEE Trans. Dielectr. Electr. Insul., vol. 23, pp. 34503457, 2016.

[18] A. A. Elserougi, I. Abdelsalam, A. M. Massoud, and S. Ahmed, "A full-bridge submodule-based modular unipolar/bipolar highvoltage pulse generator with sequential charging of capacitors," IEEE Trans. Plasma Sci., vol. 45, pp. 91-99, 2017.

[19] M. A. Elgenedy, A. A. Elserougi, A. S. Abdel-Khalik, A. M. Massoud, and S. Ahmed, "A space vector PWM scheme for fivephase current- source converters," IEEE Trans. Ind. Electron., vol. 63, no. 1, pp. 562-573, Jan. 2016.

[20] M. A. Elgenedy, A. S. Abdel-Khalik, A. Elserougi, S. Ahmed, and A. Massoud, "Fault-tolerant control of five-phase current source inverter for medium-voltage drives," in Proc. 7th IET Int. Conf. Power Electron., Mach. Drives (PEMD), 2014, pp. 1-6.

[21] K. H. Schoenbach, S. Katsuki, R. H. Stark, E. S. Buescher, and S. J. Beebe, "Bioelectrics-new applications for pulsed power technology," IEEE Trans. Plasma Sci., vol. 30, pp. 293-300, 2002.

[22] M. A. Elgenedy, A. Darwish, S. Ahmed, and B. W. Williams, "A modular multilevel generic pulse-waveform generator for pulsed electric field applications," IEEE Trans. Plasma Sci., vol. PP, no. 99, pp. 1-9, 2017.

[23] I. Abdelsalam, M. A. Elgenedy, S. Ahmed, and B. W. Williams, "Full-bridge modular multilevel submodule-based high-voltage bipolar pulse generator with low-voltage dc, input for pulsed electric field applications," IEEE Trans. Plasma Sci., vol. PP, no. 99, pp. 1-8, 2017.

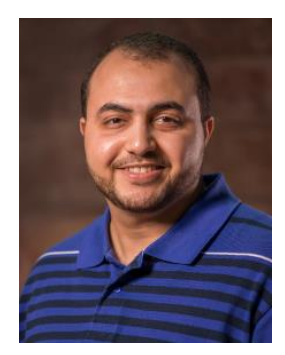

Mohamed A. Elgenedy (S'15) received the B.Sc. (with first-class honors) and M.Sc. degrees in Electrical Engineering from Alexandria University, Egypt in 2007 and 2010 respectively. Currently he is working toward the Ph.D. degree at the University of Strathclyde, Glasgow, U.K. He is also an assistant lecturer with the Electrical Engineering Department, Faculty of Engineering, Alexandria University.

In 2012, he was with Spiretronic LLC, Houston, TX, USA, as a Research Engineer. From 2013 to 2014, he was a Research Associate at Texas A\&M University at Qatar, Doha, Qatar. His research interests include high power electronics, pulse power generator, electric machine drives, energy conversion, and renewable energy.

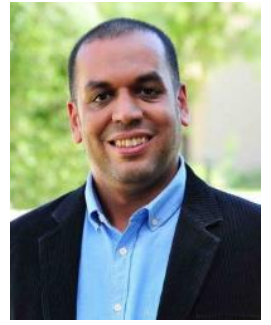

Ahmed M. Massoud (SM'11) received the B.Sc. (first class honors) and M.Sc. degrees in Electrical Engineering from Alexandria University, Egypt, in 1997 and 2000, respectively, and the Ph.D. degree in Electrical Engineering from Heriot-Watt University, Edinburgh, U.K., in 2004. He was a Research Fellow at Strathclyde University, Glasgow, U.K., from 2005 to 2008. From 2008 to 2009 , he was a Research Fellow at Texas A\&M at Qatar, Doha, Qatar. From 2009 to 2012, he was an Assistant Professor at the Department of Electrical Engineering, College of Engineering, Qatar University, where he is currently an Associate Professor in the same department. His research interests include power electronics, energy conversion, renewable energy, and power quality.

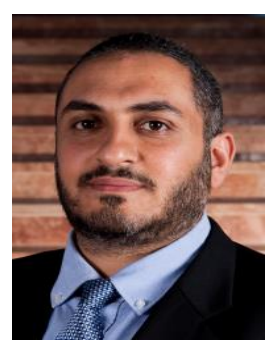

Shehab Ahmed (SM'12) was born in Kuwait City, Kuwait in July 1976. He received the B.Sc. degree in Electrical Engineering from Alexandria University, Alexandria, Egypt, in 1999; the M.Sc. and Ph.D. degrees from the Department of Electrical \& Computer Engineering, Texas A\&M University, College Station, TX in 2000 and 2007, respectively. From 2001 to 2007, he was with Schlumberger Technology Corporation working on downhole mechatronic systems. He is currently an Assoicate Professor with Texas A\&M University at Qatar, Doha, Qatar. His research interests include mechatronics, solid-state power conversion, electric machines, and drives.

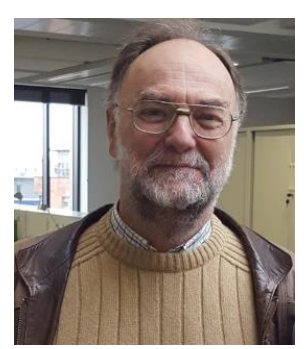

Barry W. Williams received the M.Eng.Sc. degree from the University of Adelaide, Adelaide, Australia, in 1978, and the Ph.D. degree from Cambridge University, Cambridge, U.K., in 1980. After seven years as a Lecturer at Imperial College, University of London, London, U.K., he was appointed to a Chair of Electrical Engineering at Heriot-Watt University, Edinburgh, U.K, in 1986.

$\mathrm{He}$ is currently a Professor at the University of Strathclyde, Glasgow, U.K. His teaching covers power electronics (in which he has a free internet text) and drive systems. His research activities include power semiconductor modeling and protection, converter topologies, soft switching techniques, and application of ASICs and microprocessors to industrial electronics. 